\title{
Immunological effects among workers who handle engineered nanoparticles
}

\author{
Deborah Catherine Glass, ${ }^{1}$ Mahjabeen Mazhar, ${ }^{1}$ Sue Xiang, ${ }^{2}$ Pamela Dean, ${ }^{1}$ \\ Pamela Simpson, ${ }^{3}$ Brian Priestly, ${ }^{1}$ Magdalena Plebanski, ${ }^{2}$ Michael Abramson, ${ }^{1}$ \\ Malcolm Ross Sim, ${ }^{1}$ Martine Dennekamp ${ }^{1}$
}

${ }^{1}$ Monash Centre for

Occupational and Environmental Health, School of Public Health and Preventive Medicine, Faculty of Medicine, Nursing \& Health Sciences, Monash University, 553 St Kilda Road, Melbourne, Victoria, Australia

${ }^{2}$ Department of Immunology and Pathology, Central Clinical School, Faculty of Medicine, Nursing \& Health Sciences, Monash University, The Alfred Hospital, Melbourne, Victoria, Australia

${ }^{3}$ Department of Epidemiology and Preventive Medicine, School of Public Health and Preventive Medicine, Monash University, The Alfred Centre, Melbourne, Victoria, Australia

\section{Correspondence to} Dr Deborah Catherine Glass, Monash Centre for Occupational and Environmental

Epidemiology, Monash University, The Alfred Centre, Commercial Road, Melbourne, VIC 3004, USA;

deborah.glass@monash.edu

Received 1 October 2016 Revised 24 May 2017 Accepted 30 May 2017 Published Online First 28 August 2017

\section{(1) cossarak}

To cite: Glass DC, Mazhar M, Xiang S, et al. Occup Environ Med 2017:74:868-876.

\section{ABSTRACT}

Objective To determine whether exposure of workers handling engineered nanoparticles (ENPs) may result in increased inflammation and changes in lung function.

Methods A prospective panel study compared changes in several markers of inflammation for ENP handling and non-ENP handling control workers. Nanoparticle exposure was measured during ENP handling and for controls. Lung function, fraction of exhaled nitric oxide (FeNO), C-reactive protein (CRP), blood cell counts and several serum cytokines were measured at baseline, at the end of the shift and at the end of the working week.

Results Nanoparticle exposure was not higher when ENPs were being handled; nanoparticle counts were higher in offices and in ambient air than in laboratories. There were no differences at baseline in lung function, FeNO, haemoglobin, platelet, white cell counts or CRP levels between those who handled nanoparticles and those who did not, with or without asthmatic participants. There were statistically significant increases in SCD40 and STNFR2 over the working day for those who handled ENPs. The changes were larger and statistically significant over the working week and sCD62P also showed a statistically significant difference. The changes were slightly smaller and less likely to be statistically significant for atopic than for non-atopic participants.

Conclusions Even at low ENP exposure, increases in three cytokines were significant over the week for those who handled nanoparticles, compared with those who did not. However, exposure to low and transient levels of nanoparticles was insufficient, to trigger measurable changes in spirometry, FeNO, CRP or blood cell counts.

\section{INTRODUCTION}

There is growing concern that exposure to engineered nanoparticles (ENPs) may result in adverse health effects among those who handle them in workplaces. In 2009, it was estimated that there were 2000 people in Australia engaged in nanotechnology research, 60\%-70\% of whom were doing basic or applied research rather than commercial production. $^{1}$

Nanoparticles, defined as particles with a diameter less than $100 \mathrm{~nm}$, are known to act differently from larger particles with respect to deposition and alveolar clearance. ${ }^{2}$ They can also enter the body through the skin or gastrointestinal tracts and can be transported in blood and the lymphatic system and bypass barriers within the body which

\section{What this paper adds}

- Little is known about the effects on the humans of occupational exposure to engineered nanoparticles (ENPs).

- Nanoparticle exposure was very low in the participants' laboratories.

- There were statistically significant increases in some measured cytokines over the working day and the working week for those who handled ENPs compared with those who did not.

- The changes were slightly smaller and less likely to be statistically significant for atopic than for non-atopic participants.

- The exposures did not trigger measurable changes in spirometry, FeNO, CRP or blood cell counts.

are generally impermeable to larger particles. ${ }^{3}$ As a result, substances adsorbed on the particles can be delivered intracellularly or react with cell surface receptors, potentially initiating immune responses. ${ }^{4}$ Immunological effects of nano-sized particles including both inflammation and immunosuppression have been shown in many animal studies. ${ }^{5}$ Laboratory studies also have shown that some nanoparticles can trigger the production of reactive oxygen species and cause damage to cell membranes and DNA. ${ }^{6}$

Ultrafine particles $\left(\mathrm{PM}_{1}\right.$ or $\left.\mathrm{PM}_{0.1}\right)$ but not fine particles $\left(\mathrm{PM}_{2.5}\right)$ have been shown to increase airway inflammation in mice with significant increases in inflammatory cell infiltrate and cytokines (specifically interleukin (IL)-4, IL-5, IL-10 and IL-13) and enhanced ai(rway hyper-responsiveness. ${ }^{7}$ Mice exposed to ENPs showed a significant increase in serum inflammatory markers, such as tumour necrosis factor (TNF $\alpha$ ), IL-1 and IL-6. ${ }^{8}$ Rats exposed to ENPs showed an elevation in cytokines at 24 hours which persisted for up to a week. ${ }^{9}$

While toxicological studies have identified effects in animals following exposure to ENPs, there have been relatively few studies of effects on human health. Song et $a l^{10}$ reported serious pulmonary effects following exposure to nanoparticles in seven workers. However, their interpretation of the study findings was challenged, as the effects might not have been solely attributable to nanoparticle exposure. ${ }^{1112}$ Nanoparticles may also aggravate existing 
diseases such as asthma, bronchitis and possibly neurodegenerative diseases. ${ }^{13}{ }^{14}$ Nanoparticle exposure induced oxidative stress and the formation of cytokines which remained elevated for up to 36 hours. ${ }^{15}$ Pre-shift and post-shift lung function including $\mathrm{FEV}_{1}$, forced expiratory flow rate $\left(\mathrm{FEF}_{25-75}\right)$, fraction of exhaled nitric oxide $(\mathrm{FeNO})$ and serum analyses from cement workers exposed to respirable aerosols showed inflammatory changes over the shift. There were small but significant changes for white blood cells, IL-10 and TNF $\alpha .{ }^{16}$

The aim of this study was to quantify occupational ENP exposure and to investigate short-term changes in markers of inflammation and lung function in workers handling ENPs over a working shift and a working week.

\section{METHODS}

A prospective panel (short-term cohort) study of ENP-handling workers was conducted by comparing several markers of inflammation in the blood and respiratory tract at the start of the working week, at the end of a shift and at the end of the working week. Exposure measurements were conducted when participants handled nanoparticles, on control participants and in ambient air.

Exposure measurements were made to characterise the ENP exposure of the workers at the participating workplaces during the week of the biological data collection. These were done using a NanoTracer (Philips Aerasense, Eindhoven, NL), a personal sampler located in the breathing zone of the subject which counted the number of particles sized from 10 to $300 \mathrm{~nm}$ in diameter per cubic centimetre and gave the modal diameter of the particle size distribution. This continuous, real-time monitor, logged data in 5 second averages continuously over the period of measurement. Continuous monitoring of particle counts was needed to be able to identify short-term spikes in exposure. ${ }^{1718}$

Measurements were made on participants when they were handling and not handling ENPs, as well as in ambient air outside the laboratories to establish the background nanoparticle exposure (which may contain some nanoparticles). ${ }^{1920}$ Measurements were also made on participants who did not handle ENPs and the NanoTracer was used as a static sampler in the general areas where these participants worked.

Measurement of exposure to nanoparticles took place in a sample of participants in university research laboratories and offices. Participants were drawn from all eight laboratories and work spaces. Exposure measurements were done in five laboratories where ENPs were handled. Experimental work was flexible and varied with the participant, from a few minutes handling nanoparticles to several hours in duration. Activities included making, mixing, suspending and spraying a range of nanoparticles in fume cupboards/enclosures. Control exposure measurements were also made in laboratories and work spaces where no ENPs were handled, including in four engineering laboratories where no experimental work was being carried out at the time, an insect-handling laboratory and in biomedical research offices.

\section{Biological data collection}

The participants underwent three rounds of testing:

1. At the start of the first shift of the working week.

2. At the end of the first working day.

3. At the end of the working week, usually 5 days after the start of the working week.

Because of the variable nature of research activities, it was established for each person whether or not they had ever previously handled ENPs, whether they handled them on the Monday and/or during the week of biological data collection.

The data collected on the first day included height and weight; a questionnaire on demographics, general health and respiratory symptoms; and skin prick tests to assess atopic status for four allergens (ALK-Abelló USA Allergen Extracts): house dust mite, cat, mixed grass pollens and mould and also positive (histamine) and negative (saline) controls. Atopy was defined as any positive response to one of the four allergens in the skin prick test.

The biological data collected at the three time points were:

- Lung function ( $\mathrm{FEV}_{1}$ and $\left.\mathrm{FVC}\right)$ measured using a portable electronic spirometer (ND20014S EasyOne-Line World spirometer Zürich, CH). ATS/ERS guidelines for spirometry were followed.

- Fraction of exhaled nitric oxide was measured using NIOX MINO (AE03-4001 Aerocrine, Solna, SE).

- Blood for C-reactive protein and full blood cell counts.

- Several serum cytokines and mediators were measured by cytometric bead array (BD, San Jose, California, USA): including pro-inflammatory cytokines (TNF $\alpha$, IL-6, IL-8), a pro-inflammatory mediator (GM-CSF) and other soluble serum proteins associated with inflammatory responses (sCD62P, sCD40 and sTNFR2). All serum samples were assayed at the same time. The concentration for each serum sample was determined from the standard curve of each cytokine/protein, run side-by-side with the samples.

Blood samples from nine patients with ovarian cancer (OC) (pre-treatment) were used as positive controls in the cytokine analysis. The samples of patients with OC were used as assay controls to ensure that the multiplex assay (cytometric bead array) was capable of measuring elevated levels of cytokines. ${ }^{21}$ High levels of inflammatory cytokines were detected in patients with OC and also associated with the disease progression. The assay controls were not, however, tested on the same day as the experimental samples.

\section{Statistical analysis}

Changes in the health outcome measures over the working week were compared between workers who had or had not handled nanoparticles.

When summarising categorical variables, frequencies and percentages were used. Means and SD were used to describe variables with normal distributions. The median and IQR were used to summarise continuous variables where the data were not normally distributed. Baseline demographics were compared between those who had never handled nanoparticles and those who had using t-tests for continuous variables and Fisher's exact test for categorical variables.

Multivariate regression analysis was used to analyse differences at baseline between those who had never handled nanoparticles compared with those who had previously handled them. Adjusted mean differences with 95\% CI were reported to provide an estimate of the strength of association between nanoparticle exposure and blood or spirometry outcomes.

Multivariate regression analyses with adjustment for baseline were used to estimate the mean difference in change from Monday morning to afternoon between those who handled nanoparticles on Monday and the unexposed. Multivariate regression analysis was also used to assess the mean difference in change between Monday morning and Friday between those who had handled nanoparticles during the week and those who had not. The analysis is paired with only those who have before and after readings included. 
Table 1 Summarised personal sampling exposure data from NanoTracer

\begin{tabular}{|c|c|c|c|c|c|c|c|c|c|}
\hline \multirow[b]{2}{*}{ Site } & \multicolumn{3}{|c|}{ Non-ENP handling activity } & \multicolumn{3}{|c|}{ ENP handling activity } & \multicolumn{3}{|c|}{ Ambient at laboratory/office where exposure measured } \\
\hline & $\begin{array}{l}\text { Period } \\
(\min )\end{array}$ & $\begin{array}{l}\text { Count (particles/ } \\
\mathrm{mL} \text { air) }\end{array}$ & $\begin{array}{l}\text { Mean diameter } \\
(\mathrm{nm})\end{array}$ & $\begin{array}{l}\text { Period } \\
(\min )\end{array}$ & $\begin{array}{l}\text { Count (particles/ } \\
\mathrm{mL} \text { air) }\end{array}$ & $\begin{array}{l}\text { Mean diameter } \\
(\mathrm{nm})\end{array}$ & Period (min) & $\begin{array}{l}\text { Count (particles/ } \\
\mathrm{mL} \text { air) }\end{array}$ & $\begin{array}{l}\text { Mean diameter } \\
(\mathrm{nm})\end{array}$ \\
\hline Area 1 & 229 & 4663 & 61 & 42 & 1964 & 58 & 105 & 9650 & $\mathrm{n} / \mathrm{a}$ \\
\hline Area 2 & 268 & 12554 & 46 & 75 & 9061 & 54 & 119 & 10722 & 42 \\
\hline Area 3 & 204 & 4227 & 78 & 727 & 3644 & 68 & 47 & 22620 & $\mathrm{n} / \mathrm{a}$ \\
\hline Area 4 & 150 & 11699 & 46 & 295 & 8067 & 40 & 64 & 13129 & $\mathrm{n} / \mathrm{a}$ \\
\hline Area 7 & 237 & 14090 & 41 & & & & 4 & 8434 & 35 \\
\hline
\end{tabular}

All analyses were adjusted for sex, age and smoking status, while the lung function analyses were additionally adjusted for height and age-squared to account for any non-linear age-related decline in pulmonary function. C-reactive protein (CRP) and $\mathrm{FeNO}$ were log transformed and so adjusted proportional changes in the geometric mean and 95\% CI were reported.

Data from one unexposed participant was excluded because he had a very high CRP measurement at baseline indicating a pre-existing inflammatory response.

Analyses were carried out using data from all participants and also after excluding those reporting doctor diagnosed asthma. Stata V.13 (StataCorp) was used for all analyses.

The study was approved by Monash University Human Research Ethics Committee (MUHREC A3/2012 CF12/0814 20 $12000365)$. The positive control samples used for the validation of the cytokine assays were from patients with OC under the approved study from the Royal Women's Hospital (RWH HREC project 13/32).

\section{RESULTS}

\section{Exposure}

The exposure data are summarised in table 1. Nanoparticle exposure averaged over the ENP handling periods was not found to be higher than when ENPs were not being handled. Nanoparticle counts were often higher in offices and in ambient air. The measurement technique counts particles and does not distinguish between ENPs and other nanoparticles. More details are shown in online supplementary table S1 where similar activities measured in each work area were amalgamated and the arithmetic means were calculated. Handling, making and spraying of ENPs in fume cupboards and safety cabinets did not give rise to increased nanoparticle exposure (see online supplementary figure S1) although some short-term peaks were identified associated with specific activities (eg, see online supplementary figure S2).

Grinding cement samples on an open bench resulted in high peak exposures of particles (see online supplementary figure S3). Office air, particularly those with several occupants and printing facilities, was more likely to have a higher nanoparticle count than the laboratories (see online supplementary figure S4).

Outdoor air contained more nanoparticles than the indoor air, particularly in a carpark (31571 averaged over $326 \mathrm{~min}$ ) and the main road outside Area 3 (22 620 averaged over $47 \mathrm{~min}$ ) (table 1). Nearby building work and making toast also resulted in higher numbers of particles in adjacent workstations (see online supplementary figures S5 and S6).

\section{Clinical and biological data}

The handling of ENPs was unpredictable in research laboratories. Some participants had handled ENPs in the past but not during the week of data collection.

The numbers of participants who had ever or never ever previously handled ENPs, who had handled them on the Monday and/ or during the week of biological data collection are presented in table 2. For the analyses, participants were grouped into:

- those who had ever $(\mathrm{n}=34)$ or never $(\mathrm{n}=55)$ handled ENPs, (see table 3 and online supplementary table S2 by asthmatic status);

- those who handled ENPs on Monday $(\mathrm{n}=19)$ and those who had not $(n=69)$, to examine across shift changes when handling nanoparticles (table 4 by asthmatic status and table 5 by atopic status);

- those who handled ENPs during the week of data collection $(n=27)$ and those who had not $(n=57)$, to examine across week changes when handling nanoparticles (table 5 by atopic status and table 6 by asthmatic status).

Table 2 Numbers exposed and unexposed to engineered nanoparticles

\begin{tabular}{|c|c|c|c|c|c|}
\hline & $n=89, n(\%)$ & $\begin{array}{l}\text { Exposed in across } \\
\text { Monday analyses }\end{array}$ & $\begin{array}{l}\text { Exposed in across } \\
\text { week analyses }\end{array}$ & $\begin{array}{l}\text { Not exposed in across } \\
\text { Monday analyses }\end{array}$ & $\begin{array}{l}\text { Not exposed in across } \\
\text { week analyses }\end{array}$ \\
\hline Never exposed & $55(61.8)$ & no & no & yes & yes \\
\hline Ever exposed & $34(38.2)$ & & & & \\
\hline $\begin{array}{l}\text { Previously exposed, not exposed Monday, not exposed } \\
\text { during week of testing }\end{array}$ & $6(6.8)$ & no & no & yes & yes \\
\hline $\begin{array}{l}\text { Previously exposed, exposed Monday, exposed during } \\
\text { week }\end{array}$ & 17 (19.1) & yes & yes & no & no \\
\hline $\begin{array}{l}\text { Previously exposed, not exposed Monday, exposed } \\
\text { during week }\end{array}$ & $9(10.1)$ & no & yes & yes & no \\
\hline $\begin{array}{l}\text { Previously exposed, exposed Monday, not exposed } \\
\text { during week }\end{array}$ & $2(2.2)$ & yes & yes & no & no \\
\hline
\end{tabular}




\begin{tabular}{|c|c|c|c|}
\hline & $\begin{array}{l}\text { Never handled } \\
\text { ENPs }(n=55)\end{array}$ & $\begin{array}{l}\text { Ever handled } \\
\text { ENPs }(n=34)\end{array}$ & p Value* \\
\hline Age, mean (SD) & $37.6(13.7)$ & $31.6(9.2)$ & 0.03 \\
\hline Gender-male, n (\%) & $16(29.1)$ & $23(67.7)$ & $<0.001$ \\
\hline Wheeze, n (\%) & $10(18.2)$ & $5(14.7)$ & 0.78 \\
\hline Tightness in chest, $\mathrm{n}(\%)$ & $7(12.7)$ & $2(5.9)$ & 0.47 \\
\hline $\begin{array}{l}\text { Shortness of breath at rest, } \\
\mathrm{n}(\%)\end{array}$ & $3(5.8)$ & $0(0)$ & 0.28 \\
\hline $\begin{array}{l}\text { Shortness of breath after } \\
\text { activity, } \mathrm{n}(\%)\end{array}$ & $9(16.7)$ & $7(21.2)$ & 0.78 \\
\hline Asthma, $\mathrm{n}(\%)$ & $14(25.5)$ & $1(2.9)$ & 0.01 \\
\hline Atopy, n (\%) & $29(52.7)$ & $13(40.6)$ & 0.37 \\
\hline Smoker, n (\%) & & & 0.11 \\
\hline Never & $49(89.1)$ & $26(76.5)$ & \\
\hline Current & $0(0)$ & $2(5.9)$ & \\
\hline Past & $6(10.9)$ & $6(17.6)$ & \\
\hline
\end{tabular}

${ }^{*} p$ Value from $\mathrm{t}$-tests for continuous variables and Fisher's exact test.

ENP, engineered nanoparticle.

Participants who had handled ENPs were significantly younger, more likely to be men and had significantly lower prevalence of self-reported doctor-diagnosed asthma compared with those who never handled ENPs (table 3).

At baseline, there were no statistically significant differences in blood counts, sCD40, sCD62P, CRP levels, FeNO and/or spirometry between participants who stated that they had ever and those who had never handled nanoparticles (all participants or non-asthmatic participants alone) (see online supplementary table S2). Those who had ever handled nanoparticles had a higher CRP than those who had handled nanoparticles, but the difference was not statistically significant. When asthmatics were excluded, the mean sTNFR2 in those who ever handled ENPs was statistically significantly higher compared with the nENPs handled ENPs $(p=0.04)$. No other differences were statistically significant.

When comparing the changes in parameters from Monday morning to afternoon (table 4), there was a significantly increased difference in sCD40 for all participants who had handled nanoparticles that day compared with those who had not $(p=0.01)$. There was also a statistically significantly increased difference in sTNFR2 $(p=0.003)$ and increased CRP levels in participants who had handled nanoparticles $(p=0.002)$. The analysis in non-asthmatics showed statistically significant results for the same markers, but the associations were not as strong. When stratified by atopic status (table 5), the difference was statistically significant for $\mathrm{sCD} 40(\mathrm{p}=0.001)$, sTNFR2 $(\mathrm{p}<0.001)$ and CRP $(\mathrm{p}=0.01)$ among non-atopic participants, but not among atopic participants.

When comparing the change in cytokines from Monday morning to Friday afternoon (table 6), there was a statistically significant larger increase in sCD40 and sTNFR2 for all participants who had handled nanoparticles that week compared with those who had not $(\mathrm{p}<0.001$ and $\mathrm{p}=0.002$, respectively). In addition, there was a significant increase in sCD62P for all participants who had handled nanoparticles that week compared with those who had not $(\mathrm{p}=0.003)$. The differences were still statistically significant, when asthmatics were excluded.

When stratified by atopic status across the week (table 5), the mean difference was statistically significant for sCD40 and sCD62P among atopic $(\mathrm{p}=0.01$ and $\mathrm{p}=0.04)$ and non-atopic $(p=0.02$ and $p=0.03)$ participants. The difference was only statistically significant for sTNFR2 among atopic participants $(\mathrm{p}=0.01)$.

The difference in CRP levels between two groups was not significantly different (table 6) and there was no evidence of a difference after stratifying by atopic status (table 5).

The pro-inflammatory cytokines and inflammatory mediators such as TNF $\alpha$, IL-6, IL-8 and GM-CSF were low or non-detectable in all participant samples, despite positive control samples from the patients with OC showing positive detection of those cytokines (data not shown) using the same assay kits. Online supplementary table S3 shows the detection limits for the four cytokines where all or almost all the results were below the detection limit and so could not be included in the Results tables.

\section{DISCUSSION}

The main findings were a decrease in CRP over the first day and statistically significant increases in sCD40, sCD62P and sTNFR2, particularly over the working week in those handling ENPs. These findings are consistent with an anti-inflammatory and suppressive homoeostatic cellular response in response to immune activation. Specifically, sCD40 acts to limit immune responses by interfering with the CD40/CD40L interaction between antigen presenting cells and T cells that would normally lead to their activation and expansion. In this context, it has been found elevated in patients with cancer. ${ }^{22}$

The changes observed are not expected to have clinically significant consequences, and they are much smaller, for example, than fluctuations observed due to diseases such as, for example, cancer. ${ }^{23}$ sTNFR2 as well as blocking the inflammatory activity of TNF has been correlated in previous studies with the presence of highly immune-suppressive regulatory $\mathrm{T}$ cells. ${ }^{24}$ By contrast, sCD62P, as a hallmark of platelet activation, indicates a positive response, which is counterbalanced by such homeostatic suppressive immune mechanisms. ${ }^{25}$

CRP values in the community over $3 \mathrm{mg} / \mathrm{L}$ are thought to indicate an inflammatory response that may indicate increased cardiac risk. This study did not find CRP to be elevated to this extent.

There were no significant changes in other inflammatory cytokines, haematological parameters, lung function or airway inflammation related to ENP exposure. There were too few asthmatic participants in the exposed group to examine them separately $(n=2)$. When stratified by atopic status, exposed non-atopic participants show a larger increase in sCD40 and sTNFR2 than the unexposed atopics over Monday. Over the week, however, exposed atopic and non-atopic participants showed both significant increasescompared with the unexposed. This suggests that some inflammation was occurring as a result of the exposure to ENPs.

The observed changes in soluble immune and inflammatory factors did not reach the levels identified in previously reports $^{2627}$ as being associated with acute lung or peripheral pathology or disease. However, the fact that significant changes were observed associated with nanoparticle exposure suggests that persistent exposure could be a chronic immunomodulatory factor capable of modifying baseline levels of key regulatory immune factors. The impact of the change of such basal levels on subsequent environmental challenges (eg, an infection) has the potential to affect the clinical resolution of such subsequent exposures, and it bears further investigation. For example, non-specific effects of vaccines on the innate immune system alter subsequent immunity to infections. ${ }^{28}$ 


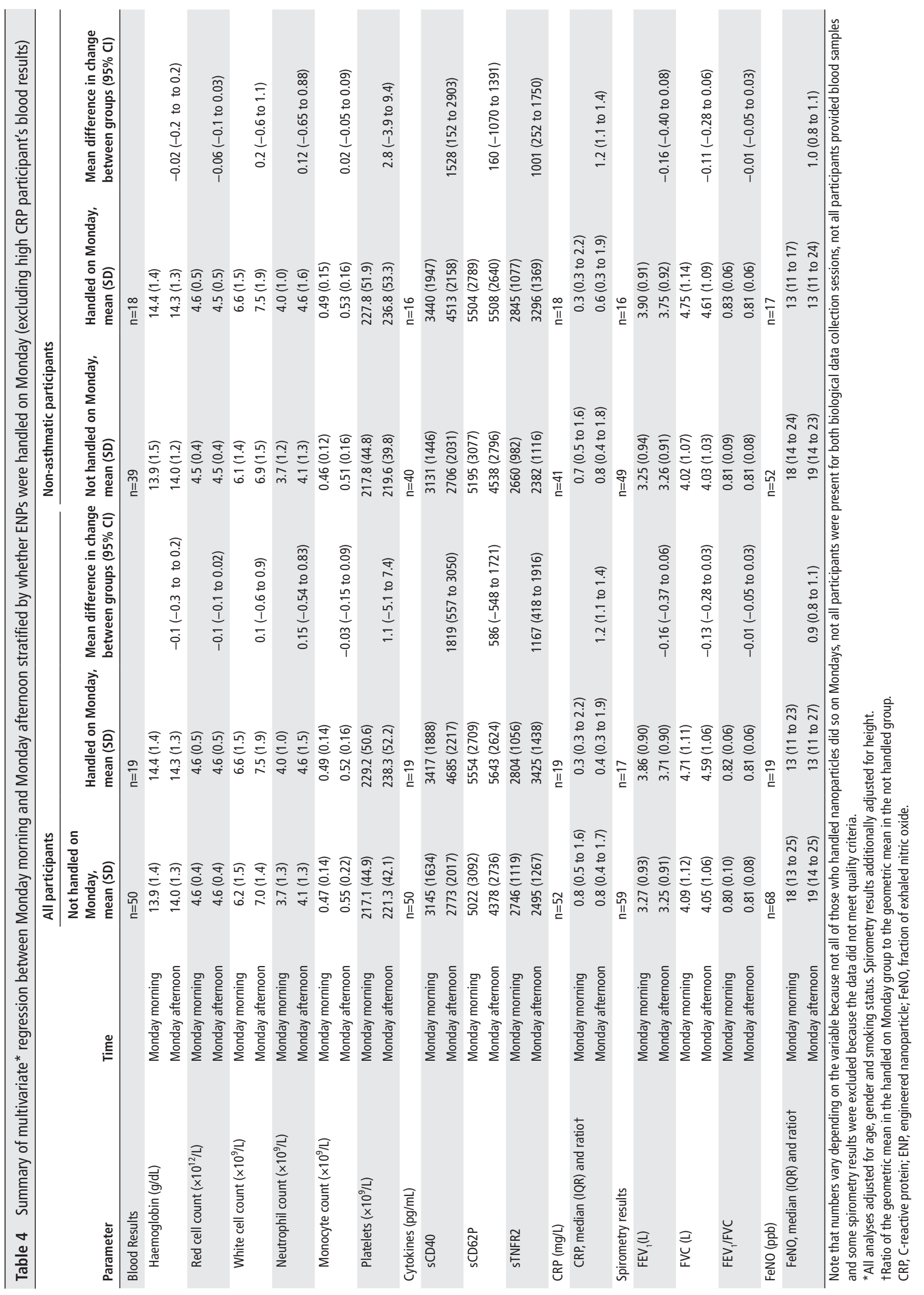




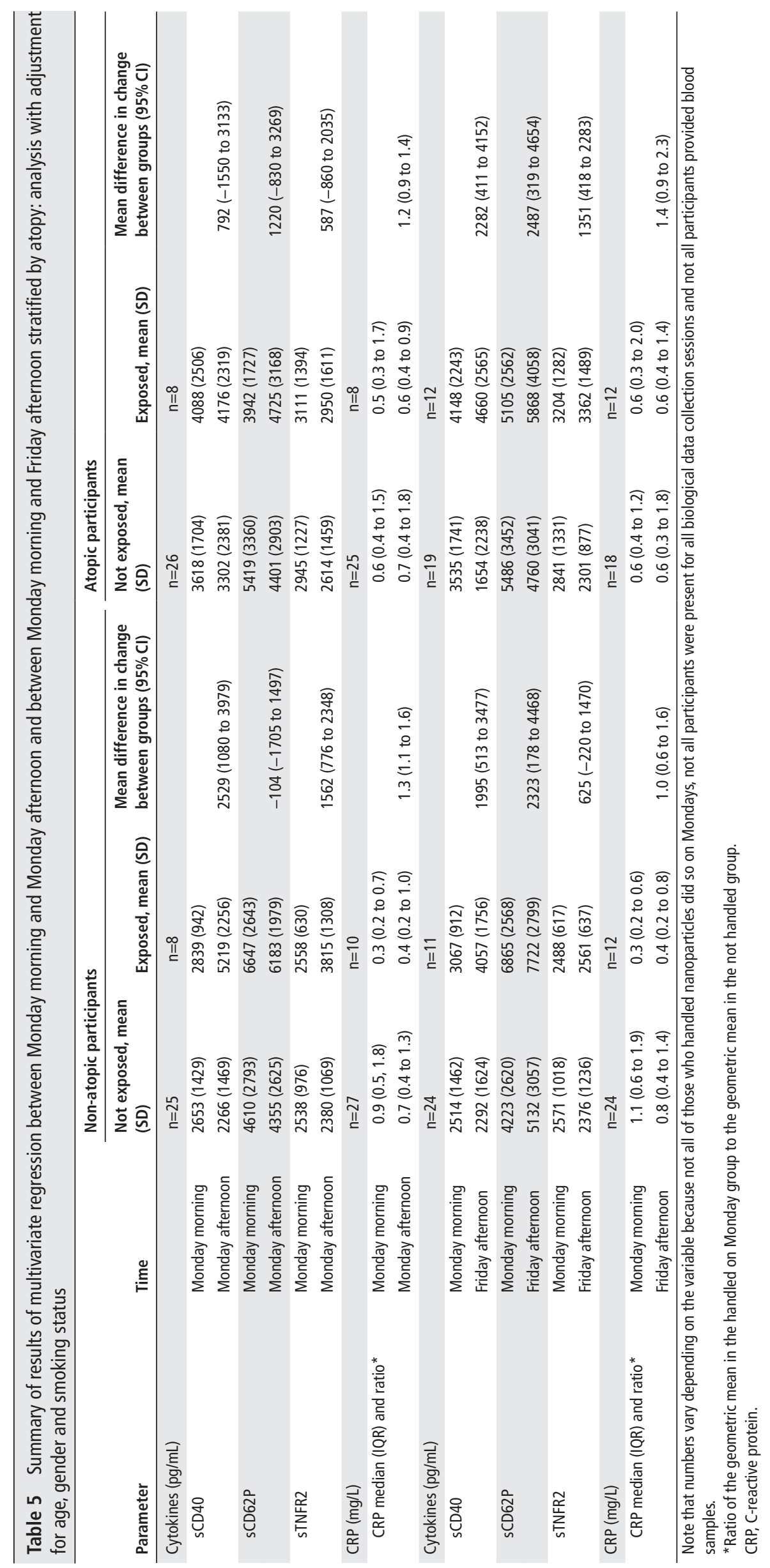




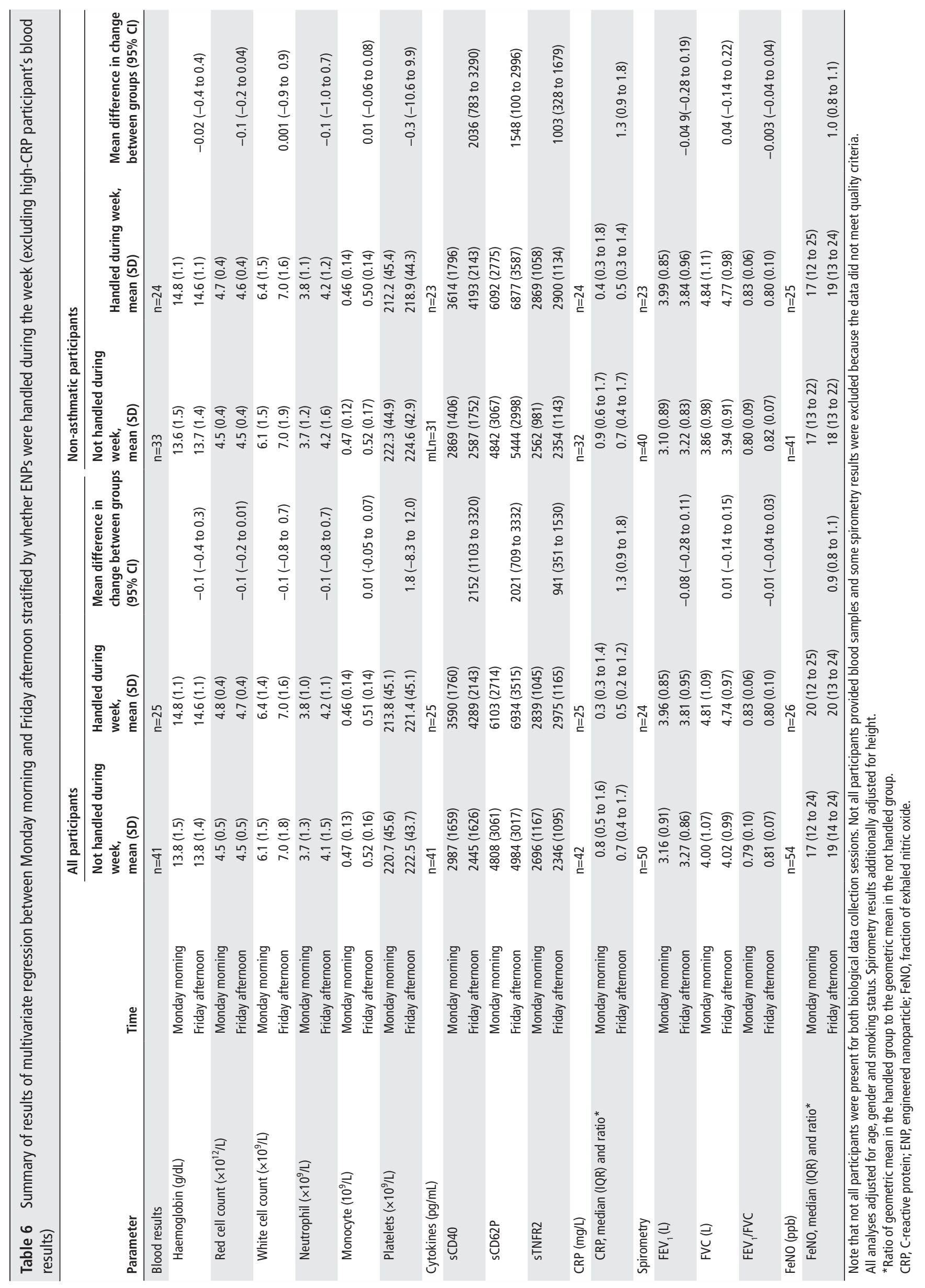


The findings are consistent with the limited number of studies investigating the association between outdoor particulate air pollution (which also contains particles in the nanometre size range) and immunological responses. Positive associations have been found between particulate matter exposure and sCD $62 \mathrm{P}^{2930}$ and sCD40L. ${ }^{30} 31$ Furthermore, TNF has been suggested to be associated with outdoor particulate air pollution. ${ }^{32}$ The association between CRP and outdoor air pollution is inconsistent. ${ }^{33}$

The risks associated with number of outcomes were examined using 95\% CI. When more than 20 risk estimates are made, it becomes more likely that one of these may be a chance finding. It is important, therefore, to look at the overall pattern of results. In this study, the cytokine results are similar across Monday and across the week, suggesting that these are robust findings.

\section{Exposure}

Nanoparticles tend to agglomerate forming larger particles, when they come into contact with each other in air currents; therefore, to get the most accurate measurement, the personal sampler was fixed in the breathing zone of the participant.

Exposure measurement challenges included particles entering the laboratory at higher concentrations than those inside, affecting the baseline or background exposures, for example, building work (see online supplementary figure S5) and making toast (see online supplementary figure S6). Laboratories appeared to have fewer nanoparticles than did offices. Nanoparticles are emitted from photocopiers ${ }^{34}$ and printers ${ }^{35}$ which may account for the comparatively higher measurement in offices compared with laboratories.

The participants were working with one of a variety of agents including polystyrene nanoparticles, zinc-cadmium nanoparticles, hydroxyapatite nanopowder, carbon nanotubes, copper chloride nanoparticles, copper nanowires, gold nanoparticles, iron oxide and silver nanoparticles. Unfortunately, there were too few individuals working with any one agent to investigate differences between agents in a meaningful way. Despite this heterogeneity, we were able to observe significant consistent effects on a number of specific immune parameters. We believe that this is useful as pinpointing these parameters is informative to test in any future large-scale studies in this area.

It is not clear how generalisable these findings are, in that the laboratories varied in activities and the ENPs were handled. Exposure prevention strategies had been implemented at the worksites in this study where ENPs were handled. ${ }^{36}{ }^{37}$ Most particles were handled after suspension in fluid. The participants almost always wore gloves when handling ENPs and prepared and sprayed suspensions in ventilated cupboards, fume cupboards or other safety cabinets.

Most staff and students in these research laboratories did not handle ENPs. Both the control and exposed participants were exposed to nanoparticles from other sources such as office and external air, in some cases at much higher levels. Those who did handle ENPs, only did so for a small proportion of their time. Set working hours could not be identified for the staff and students in the laboratories because of the demands of specific experiments. The ENP handling tasks were frequently very short term and often unrepeatable so that repeated measurements were often not available. In future studies, repeated exposure measurements on the same activities would better measure this type of exposure. ${ }^{38}$

When carbon nanotubes were handled, the precautions were increased, so that they were handled inside a glove bag within the fume cabinet and the experimenter wore a full-face negative pressure respirator. After the fibres had been included in a matrix, the embedded material was handled on an open bench and higher exposures were measured, but the experimenter wore a full-face negative pressure respirator. Much of the dust generated would have been from the matrix of cement dust.

Some short-term activities such as use of the centrifuge resulted in short-term peaks in the laboratory (eg, see online supplementary figures 2 and 3). Sonication of nanoparticles in solution is a common practice in these laboratories and this practice can release mist into the atmosphere. ${ }^{39}$ There was a clear increase in nanoparticle concentration in only one laboratory as measured with the NanoTracer. The exposures were not directly comparable to those of Lee $e \mathrm{al}^{17}$ because their instrumentation detected particles with a different size range. However, they measured concentrations of between 224622 and 2328608 particles $/ \mathrm{cm}^{3}$ in a workplace manufacturing silver nanoparticles. Methner et al measured exposure in research laboratories and using a CPC counting $10-1000 \mathrm{~nm}$ diameter particles. ${ }^{19}$ In their study, they found that background particle number concentrations ranged from 700 to 19500 particles $/ \mathrm{cm}^{3}$ of air and background-adjusted concentrations (background-adjusted by subtraction of the background measurements) ranged between 1600 and 5000 particles $/ \mathrm{cm}^{3}$. The differences between laboratories may result from several factors: first real differences, the ENPs were generated and the control measures were used to reduce exposure; second, in the laboratory, background particle count, eg, openable windows, may lead to the infiltration of ambient air with higher nanoparticle counts and differences in the effectiveness of the filtration of air supplied to the laboratory and, lastly, in the size range covered by the instruments used to count the particles.

The NanoTracer may undercount particles below $20 \mathrm{~nm} .{ }^{4041}$ The data may then have underestimated the exposure, particularly at the lower end of the particle range. The tube extension provided with the NanoTracer was not used as this was found to reduce the number of particles counted.

\section{CONCLUSIONS}

Increases were seen in levels of cytokines sCD40, sCD62P and sTNFR2 and CRP across a day following exposure to very low ENP levels against a background of nanoparticles in office and external air. The increases in three cytokines were significant over the week for those who handled nanoparticles compared with those who did not. The changes were slightly smaller and less likely to be significant when asthmatic participants were excluded, suggesting that asthmatics were at greater risk of this increase in cytokines, although there were only two exposed asthmatics. Atopic participants show increased in cytokines over the week, compared with control participants but not over the first day of exposure week.

Exposure to the low and transient levels of nanoparticles in the workplaces included in our study was insufficient to trigger measurable changes in spirometry, FeNO measurements, CRP, haemoglobin platelet or blood cell counts.

These data suggest that exposure in the types of laboratories tested would be unlikely to cause any significant immunological effects in workers handling ENPs intermittently. However, evaluating nanoparticle exposure in diverse environments and with nanoparticles with potentially different immunomodulating properties allowed this study to identify consistent underlying immune effects associated with handling ENPs.

Acknowledgements MP is an NHMRC SRF 1059409. Virtual Accident, Glen Waverley, VIC 3150, Australia, allowed time for PMD to contribute to the paper. 
Contributors DG, BP, MP, MA, MS and MD obtained the funding, designed and oversaw the study. DG, MM, PD and MD carried out the data collection and cleaning. SX carried out the cytokine analyses. PS carried out the statistical analyses. DG wrote the draft manuscript which has been seen, edited and approved by the other authors.

Funding $D G, B P, M P, M A, M S$ and $M D$ received funding from the Australian Government National Health and Medical Research Council for the study which has been completed.

Competing interests None declared.

Ethics approval Monash University HREC and Alfred Hospital HREC.

Provenance and peer review Not commissioned; externally peer reviewed.

(c) Article author(s) (or their employer(s) unless otherwise stated in the text of the article) 2017. All rights reserved. No commercial use is permitted unless otherwise expressly granted.

\section{REFERENCES}

1 Australian Academy of Science Nanotechnology in Australia: trends, applications and collaborative opportunities. Canberra 2009

2 Ostiguy C, Soucy B, Lapointe G, et al; Health effects of nanoparticles. Second Edition, 2008. Report R-589: Institut de Recherche Robert-Sauvé en santé et en sécurité du travail (IRSST) Montreal, Québec.

3 Harford A, Edwards J, Priestly B, et al. Current OHS practices for the Australian nanotechnology industry: a position paper by the NanoSafe Australia Network. JOHSANZ 2007;23:315-31.

4 Bakand S, Hayes A, Dechsakulthorn F. Nanoparticles: a review of particle toxicology following inhalation exposure. Inhal Toxicol 2012;24:125-35.

5 Mohamud R, Xiang SD, Selomulya C, et al. The effects of engineered nanoparticles on pulmonary immune homeostasis. Drug Metab Rev 2014;46:176-90.

6 Bruschi S, Thomas S, Consulting F. A review of the potential occupational health and safety implications of nanotechnology. Canberra: Australian Safety and Compensation Council, 2006.

7 de Haar C, Hassing I, Bol M, et al. Ultrafine but not fine particulate matter causes airway inflammation and allergic airway sensitization to co-administered antigen in mice. Clin Exp Allergy 2006;36:1469-79.

8 Park EJ, Kim H, Kim Y, et al. Carbon fullerenes (C60s) can induce inflammatory responses in the lung of mice. Toxicol App/ Pharmacol 2010;244:226-33.

9 Kobayashi N, Naya M, Endoh S, et al. Comparative pulmonary toxicity study of nano$\mathrm{TiO}(2)$ particles of different sizes and agglomerations in rats: different short- and longterm post-instillation results. Toxicology 2009;264:110-8.

10 Song Y, Li X, Du X. Exposure to nanoparticles is related to pleural effusion, pulmonary fibrosis and granuloma. Eur Respir J 2009;34:559-67.

11 Brain JD, Kreyling W, Gehr P. Letter to the Editor (and reply). ERJ 2010;35.

12 Inoue K, Takano H. Letter to the Editor (and reply). ERJ 2010;35.

13 Hussain S, Thomassen LC, Ferecatu I, et al. Carbon black and titanium dioxide nanoparticles elicit distinct apoptotic pathways in bronchial epithelial cells. Part Fibre Toxicol 2010;7:10.

14 Oberdorster G. Safety assessment for nanotechnology and nanomedicine: concepts of nanotoxicology. Journal of internal medicine. [Research Support, N.I.H., Extramura Research Support, U.S. Gov't, Non-P.H.S.] 2010;267:89-105.

15 Khatri M, Bello D, Gaines P, et al. Nanoparticles from photocopiers induce oxidative stress and upper respiratory tract inflammation in healthy volunteers. Nanotoxicology 2013;7.

16 Fell AK, Notø H, Skogstad M, et al. A cross-shift study of lung function, exhaled nitric oxide and inflammatory markers in blood in norwegian cement production workers. Occup Environ Med 2011;68:799-805.

17 Lee JH, Ahn K, Kim SM, et al. Continuous 3-day exposure assessment of workplace manufacturing silver nanoparticles. Journal of Nanoparticle Research 2012;14.

18 Leppänen $\mathrm{M}$, Lyyränen J, Järvelä $\mathrm{M}$, et al. Exposure to $\mathrm{CeO}(2)$ nanoparticles during flame spray process. Nanotoxicology 2012;6:643-51.

19 Methner M, Hodson L, Dames A, et al. Nanoparticle Emission Assessment Technique (NEAT) for the identification and measurement of potential inhalation exposure to engineered nanomaterials_-part B: results from 12 field studies. J Occup Environ Hyg 2010;7:163-76

20 Methner M, Hodson L, Geraci C. Nanoparticle Emission Assessment Technique (NEAT) for the identification and measurement of potential inhalation exposure to engineered nanomaterials - part A. J Occup Environ Hyg 2009;7. \{Methner, 2010 \#300\}.

21 Madondo MT, Tuyaerts S, Turnbull BB, et al. Variability in CRP, regulatory T cells and effector $T$ cells over time in gynaecological cancer patients: a study of potential oscillatory behaviour and correlations. J Trans/ Med 2014;12:179.

22 Huang J, Jochems C, Talaie T, et al; Elevated serum soluble CD40 ligand in cancer patients may play an immunosuppressive role Blood. 120, 2012.

23 Madondo MT, Tuyaerts S, Turnbull BB, et al. Variability in CRP, regulatory T cells and effector T cells over time in gynaecological cancer patients: a study of potential oscillatory behaviour and correlations. J Trans/ Med 2014;12:179.

24 Minigo G, Woodberry T, Piera KA, et al. Parasite-dependent expansion of TNF receptor II-positive regulatory $T$ cells with enhanced suppressive activity in adults with severe malaria. PLoS Pathog 2009;5:e1000402.

25 Figueroa-Vega N, Moreno-Frías C, Malacara JM. Alterations in adhesion molecules, pro-inflammatory cytokines and cell-derived microparticles contribute to intima-media thickness and symptoms in postmenopausal women. PLoS One 2015;10:e0120990.

26 Bauer TT, Montón C, Torres A, et al. Comparison of systemic cytokine levels in patients with acute respiratory distress syndrome, severe pneumonia, and controls. Thorax 2000;55:46-52.

27 Zhang Y, Li J, Zhan Y, et al. Analysis of serum cytokines in patients with severe acute respiratory syndrome. Infect Immun 2004;72:4410-5.

28 Fish EN, Flanagan KL, Furman D, et al. Changing oral vaccine to inactivated Polio vaccine might increase mortality. Lancet 2016;387:1054-5.

29 Delfino RJ, Staimer N, Tjoa T, et al. Air pollution exposures and circulating biomarkers of effect in a susceptible population: clues to potential causal component mixtures and mechanisms. Environ Health Perspect 2009;117:1232-8.

30 Zhang J, Zhu T, Kipen $\mathrm{H}$, et al. Cardiorespiratory biomarker responses in healthy young adults to drastic air quality changes surrounding the 2008 Beijing Olympics: HEl Health Review Committee. Res Rep Health Eff Inst 2013;174:5-174.

31 Rückerl R, Greven S, Ljungman P, et al. Air pollution and inflammation (interleukin-6, C-reactive protein, fibrinogen) in myocardial infarction survivors. Environ Health Perspect 2007:115:1072-80.

32 Vawda S, Mansour R, Takeda A, et al. Associations between inflammatory and immune response genes and adverse respiratory outcomes following exposure to outdoor air pollution: a HuGE systematic review. Am J Epidemiol 2014;179:432-42.

33 Li Y, Rittenhouse-Olson K, Scheider WL, et al. Effect of particulate matter air pollution on C-reactive protein: a review of epidemiologic studies. Rev Environ Health 2012;27:133-49.

34 Bello D, Martin J, Santeufemio C, et al. Physicochemical and morphological characterisation of nanoparticles from photocopiers: implications for environmental health. Nanotoxicology 2013;7.

35 Morawska L, McGarry P, Morris H, et al; Measurements of particle emissions from Nanotechnology Processes, with Assessment of Measuring Techniques and Workplace controls. Safe Work Australia: The International Laboratory for Air Quality and Health, 2012.

36 Anonymous. Working safely with nanomaterials in research \& development. United Kingdom: The UK NanoSafety Partnership Group (UKNSPG), 2012.

37 NIOSH. General Safe Practices for working with Engineered Nanomaterials in Research Laboratories. Cincinnati, Ohio: NIOSH2012 Contract No 2012:147

38 Ramachandran G, Ostraat M, Evans DE, et al. A strategy for assessing workplace exposures to nanomaterials. J Occup Environ Hyg 2011;8:673-85.

39 Johnson DR, Methner MM, Kennedy AJ, et al. Potential for occupational exposure to engineered carbon-based nanomaterials in environmental laboratory studies. Environ Health Perspect 2010;118:49-54.

40 Buonanno G, Jayaratne R, Morawska L, et al. Metrological Performances of a diffusion charger particle counter for personal monitoring. Aerosol Air Qual Res 2014:14:156-67.

41 Marra J, Voetz M, Kiesling H-J. Monitor for detecting and assessing exposure to airborne nanoparticles. Journal of Nanoparticle Research 2010;12:21-37. 